\title{
Finite Element Analysis of Shell-First and Longitudinally Reinforced Frame-Based Wooden Ships
}

\author{
Nathan Helfman ${ }^{1}$ (D) $\cdot$ Boaz Nishri $^{2} \cdot$ Deborah Cvikel $^{1}$ (D) \\ Published online: 20 May 2019 \\ (c) The Author(s) 2019, corrected publication 2019
}

\begin{abstract}
During the period between the 5th century BC and the 6th century AD, two ship construction technologies were prevalent around the Mediterranean Sea: shell-first and framebased. The shell-first concept was of a strong rigid hull, comprising edge-joined strakes reinforced by transverse frames which were not joined to the keel. In the frame-based technique, transverse frames were connected to the keel to form the skeleton, and the strakes were then nailed to the frames. The hull was strengthened with longitudinal reinforcements. These concepts did not exist in isolation, and at times both techniques were combined. An initial global finite element study (FEA) which analyzed the two technologies, the shell-first Ma'agan Mikhael (400 BC), and the frame-based Dor 2001/1 (6th century $\mathrm{AD})$, revealed that the ships were on a structural par. In that same study, a controlled FEA experiment on generic models was constructed to simulate shell-first and frame-based ships, showing, however, that the shell-first technique exhibited significantly higher structural integrity than the frame-based method. These results prompted a secondary study to explore the mechanical-structural contribution of longitudinal reinforcements to framebased constructs. Using the same frame-based generic model as in the previous study, longitudinal reinforcements were added in various configurations. The FEA results from this study demonstrated that three critical interdependent factors determined the relative strengths of shell-first and frame-based techniques: the number of transverse frames, the number of longitudinal reinforcements, and their relative locations.
\end{abstract}

Keywords Shell-first · Frame-based · Finite element analysis · Longitudinal reinforcement

\section{Introduction}

The motivation for the current research was derived from a previous study which explored whether there was a specific structural and mechanical advantage inherent to the frame-based technique which contributed to its dominance (Helfman et al. 2018).

Nathan Helfman

nathan.helfman@gmail.com

1 Department of Maritime Civilizations and the Leon Recanati Institute for Maritime Studies, University of Haifa, 3498838 Haifa, Israel

2 CorFlow Ltd. Aerodynamic and Flow Technologies, Haifa, Israel 
For that study, this hypothesis was proposed: The inherent mechanical advantages of the frame-based technique contributed to the transition from shell-first to frame-based ships. The 'inherent advantages' would be manifested in degrees of rigidity and reduction of internal stress on the hull. This experiment, which applied standard computerized analysis techniques, demonstrated overall global structural parity. However, using simplified generic models, the shell-first design exhibited a significant structural advantage, thus refuting the above hypothesis. The subject of this paper deals with the question, 'What structural and mechanical measures were necessary and employed by shipwrights to achieve structural parity to attain ultimate dominance?'. The authors, being motivated by archaeological evidence, engineering principals and the promptings of scholars, including Pomey, Reith, Kahanov (Pomey et al. 2012:236) and van Doorninck (van Doorninck 1976), developed a further hypothesis: 'Increasing the number of hull frames and longitudinal reinforcements establishes equal levels of increased rigidity and reduction of stress in shell-first and frame-based ship hulls'.

This engineering-archaeological research approach to the transition from shell-first to frame-based ship construction cannot disregard the peripheral constraints, which include simplification of construction, less use of skilled workers, ideology, tradition, economics, purpose, environment and materials (Adams 2003:29). Despite what has been shown to be the mechanical advantages of the shell-first core structure, by the close of the 1st millennium AD, frame-based wooden hulls became ubiquitous in the Mediterranean. The proliferation of the frame-based hull seems to have been evolutionary, involving a simultaneous convergence of events, such as timber shortage, laborintensive maintenance, social unrest, war profiteering, and technological changes. Given this evolutionary process, our objective for this study and its precursor, was not to determine which construction technique was 'better' or 'worse', nor whether structural integrity would necessarily account for this protracted transition. Rather, based on archaeological data, it aims to quantitatively examine what mechanical-structural properties may have contributed to the frame-based technology to be at least, as the late Professor Yaacov Kahanov posited, "good enough."

Both studies employed an engineering analysis tool known as finite element analysis (FEA). FEA is a computerized numerical technique used for solving field problems in various engineering disciplines. For the initial study, given the numerous shell-first and framebased shipwrecks, ranging from the Uluburun, Kyrenia, and Madrague de Giens, to the Serçe Liman1, the selection of the objects of our analysis was challenging. The criteria for selection were based on the amount of accessible detailed and structural information, and the extent to which the shipwreck qualified as archetypical. The Ma'agan Mikhael (400 BC) and Dor 2001/1 (6th century AD) shipwrecks, both excavated off the coast of central Israel, five kilometers apart, were considered ideally suited.

The data from the well-preserved shell-based hull of the Ma'agan Mikhael ship were extensive (Linder et al. 2003:53). Furthermore, its principal researcher, the late Professor Yaacov Kahanov, was readily available during the course of the study. The Dor 2001/1 shipwreck, constructed using a frame-based method (Kahanov and Mor 2014:41), was well preserved, and is considered one of the earliest examples of frame-based ship technology, pre-dating the Serçe Limanı (1025 AD) by about 500 years. Radiocarbon analyses of short-living organic specimens and pottery typology dated them 1000 years apart (Linder et al. 2004:243). Moreover, for both shipwrecks, reconstructed hull lines drawings were available, along with detailed information regarding their wood materials. The study's two subjects set the stage for further comparative and variability testing of other archetypical shipwrecks of this transitional period. 
CAD models (Fig. 1) were developed from archaeological and theoretical reconstructions at a 1:1 scale. The ships, though dimensionally similar in length, beam and volume, differed significantly in their method of construction and hull shape. The Dor 2001/1 is described as a flat-bottomed Byzantine ship of basically riverine origin (Kahanov and Mor 2014:41), while the Ma'agan Mikhael was a seagoing merchantman with a wine-glass hull cross-section, assumed to be constructed in the Aegean area (Linder et al. 2004). These structural differences in themselves would be worthy of future research in determining whether merchant river incursions served as a force in the practicability in applying a frame-based solution. This frame-based river study would conceivably begin with Lucan's Pharsilia, Book IV, Caesar in Spain: "When Sicoris kept his banks, the shallow light/Of hoary willow bark they build, which bent/On hides of Oxen, bore the weight of a man and swam the torrent/This on sluggish Po Venetians float...". Among many other examples, Roman frame-based presence on the Main and Rhine (2 AD) is cited by Hockmann (Hockmann 1993:126).

The analyses of the initial study, which were performed under stillwater conditions on solid contiguous bodies of both ships, were intended to test failure under combined multiple loads (Fig. 2). Stillwater hogging and sagging tests were also conducted on both vessels, neglecting wind and cargo loads. These analyses, known as 'global strength assessment criteria for hull design loads', are prescribed by the DNV GL, Det Norske Verita and Rules for Classification and Construction of Ship Technology, Special Craft, Yachts and Boats up to $24 \mathrm{~m}$ (DNV GL 2015:5).

The assessment is based on two parameters of structural integrity: rigidity/stiffness (Eq. 1), and resistance to stresses,

$$
k=\frac{F}{\delta}
$$

where for rigidity and stiffness, $k=$ rigidity quotient, $F=$ applied load (in force units) and $\delta=$ total deflection (in linear dimensions).

Stress resistance is measured using von Mises testing, a technique employed by various engineering disciplines for testing structural failure. These stresses, which exist internally under the imposition of external loads on a body, are known as principal stresses. They occur simultaneously, to different degrees, in three different spatial dimensions: $\mathrm{X}, \mathrm{Y}$, and $\mathrm{Z}$ (Fig. 3) from which von Mises testing resolves them into a singularly defined 'averaged' or resultant stress.
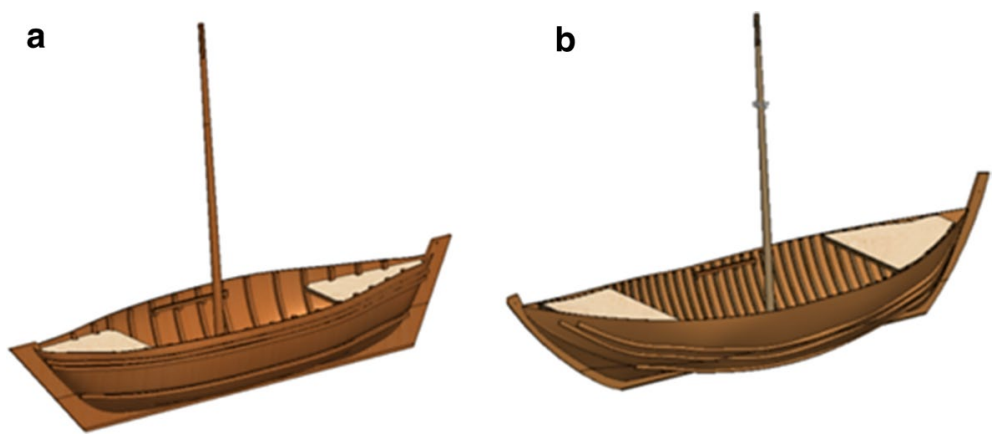

Fig. 1 CAD reconstructions: a Ma'agan Mikhael; b Dor 2001/1 hulls 


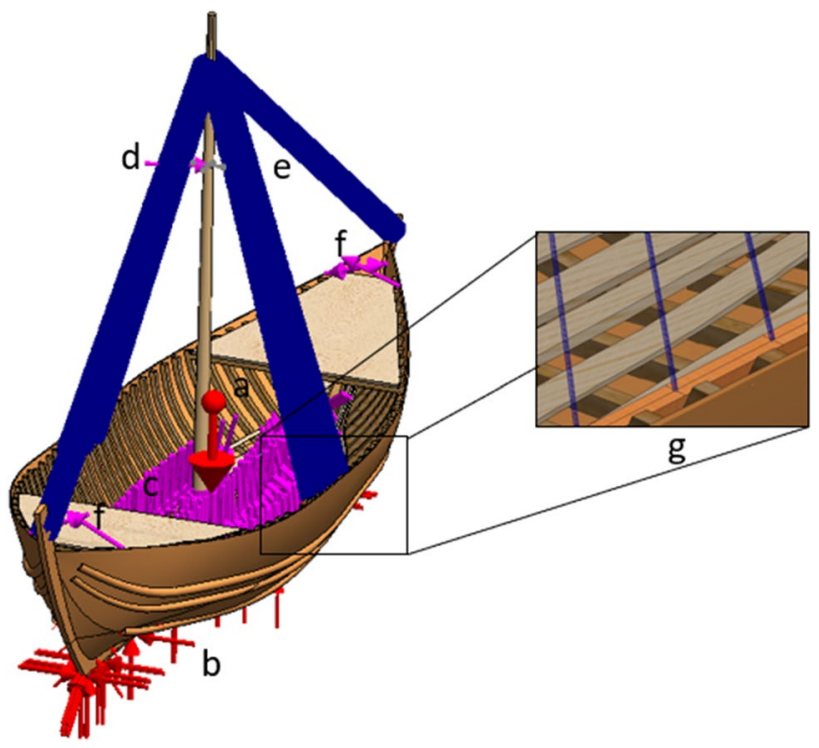

Fig. 2 Multiple static external loads on both ships' hulls as represented by Dor 2001/1: a gravity; b stillwater hydrostatic; $\mathbf{c}$ cargo load; $\mathbf{d}$ superimposed wind force; e rigging force using (stiffness adapted spring connectors); f torsion; $\mathbf{g}$ rigging detail

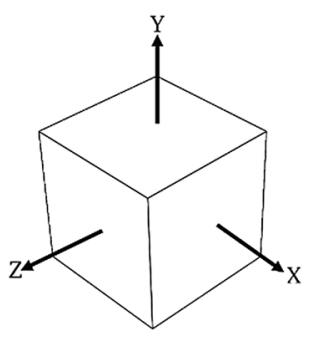

Fig. 3 Spatial directions

Failure occurs if the resultant value is equal to or greater than the yield stress in the material, causing loss of elasticity (Eq. 2).

$$
\sigma_{V M} \geq \sigma_{y}
$$

where $\sigma_{V M}$ is von Mises stress and $\sigma_{y}=$ yield stress.

The global analyses revealed that the hulls were at a structural par with high degrees of rigidity and von Mises stress values well below mechanical yield, roughly $70 \mathrm{MPa}$ (Fig. 4) (Helfman et al. 2018:96). MPa (Megapascal) is a measurement designating a stress value where the load force is divided by the area upon which it is imposed (see glossary of terms).

Although the global analyses indicated a comparative structural-mechanical parity between the two ships, their geometric and material dissimilarities dictated the design of an experimental environment which would allow isolation and manipulation of the variables involved in the shell-first/frame-based transition. The discipline of FEA requires the simplification of 


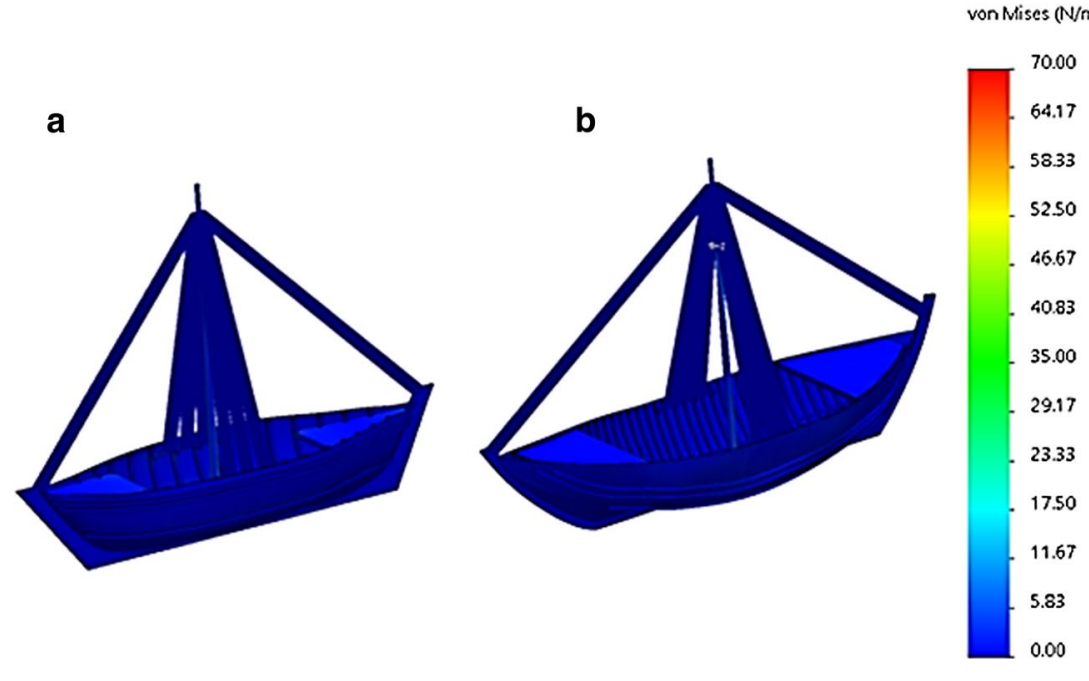

Fig. 4 Comparative von Mises results of multiple stress load conditions, demonstrating equal stress levels on both ships. All stress levels of rigging and wooden components were below their yield values: a Ma'agan Mikhael ship; b Dor 2001/1 ship

geometric parameters. This initial experiment, therefore, ignored hull shape differences while maintaining beam and length, integrating the essential structural parameters involving:

- Keel-frame relationships

- Shell-first hull contiguity

- Frame-based hull planking

- Shell-first plank-frame relationship

- Averaged frame cross-sections

- 'Hybrid' materials

- Symmetrical sections (half length, half width)

Based on this paradigm, structurally generic and representative shell-first and framebased models were generated, embodying the characteristic properties of the Ma'agan Mikhael and Dor 2001/1 ships. A testing plan (Fig. 5) was devised by applying loads on generic hulls in critical directions to test the initial hypothesis.

Summarizing the results (Figs. 6, 7), averages taken for stress and rigidity revealed a consistent and significant advantage of the shell-first method over the frame-based method in withstanding plastic deformation and failure. For frame-based models, the results clearly indicated that the addition of frames consistently decreased von Mises stress levels, while increasing rigidity.

Hence, the hypothesis of the experiments preceding those of this research, i.e., positing that the inherent mechanical advantages of the frame-based technology contributed to the transition from shell-first to frame-based ships would appear to be refuted. Indeed, the results appear unequivocal, but raise the question: how was the structural gap bridged? The above results served as the rationale and impetus for the continuing investigation which explores to what extent structural configuration and longitudinal reinforcements bridge the structural gap between shell-first and frame-based wooden ships. The results also echo the 

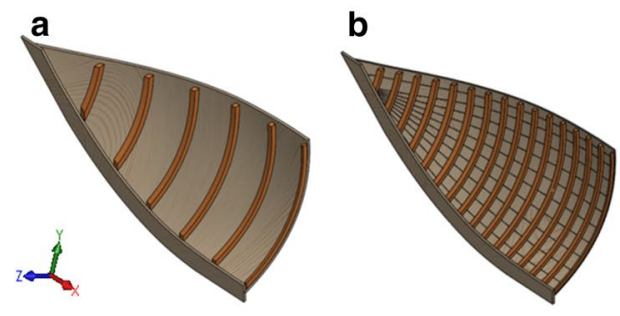

\begin{tabular}{|c|c|c|}
\hline $\begin{array}{c}\text { Load Direction } \\
\text { L }\end{array}$ & Load Value (N) & Schematic Representation \\
\hline$+X$ & 50,000 & \\
\hline$-Y$ & 20,000 & \\
\hline$+Y$ & 20,000 & \\
\hline$+Z$ & 100,000 & \\
\hline
\end{tabular}

Fig. 5 Testing plan on generic models imposing loads (in Newtons) in critical directions: a shell-based; b frame-based

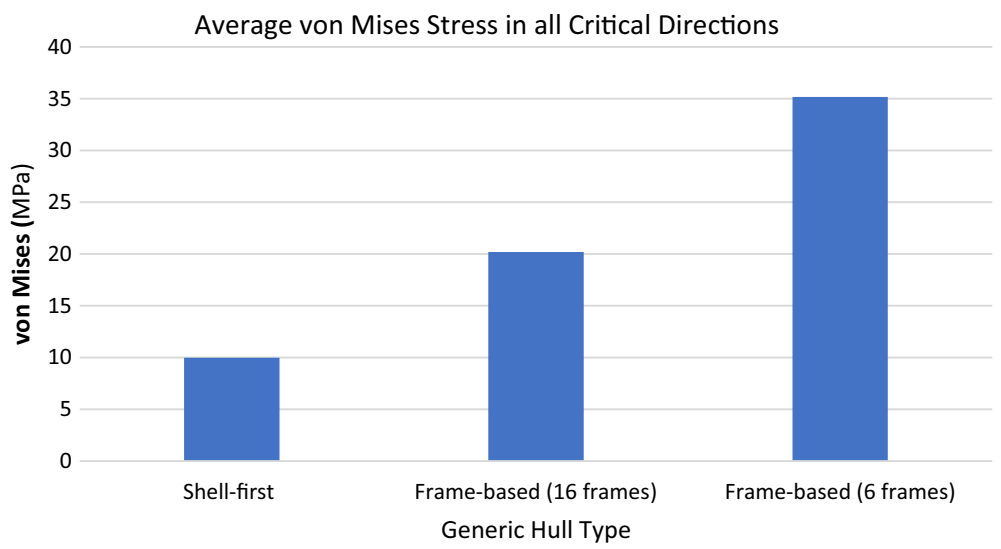

Fig. 6 Average von Mises stress in all critical directions

enjoinment of Pomey et al., that "The longitudinal strength of the hull should be evaluated when considering characteristics of the skeleton concept" (Pomey et al. 2012:236).

\section{Methods and Materials}

In the pursuit of continuity and consistency with the initial simulation experiment, the frame material simulated was Quercus petraea, while the hull planks consisted of Pinus brutia. Ships of antiquity were not constructed with dimensionally consistent wooden planks and frames of Pinus brutia and Quercus petraea. However, considering the need 


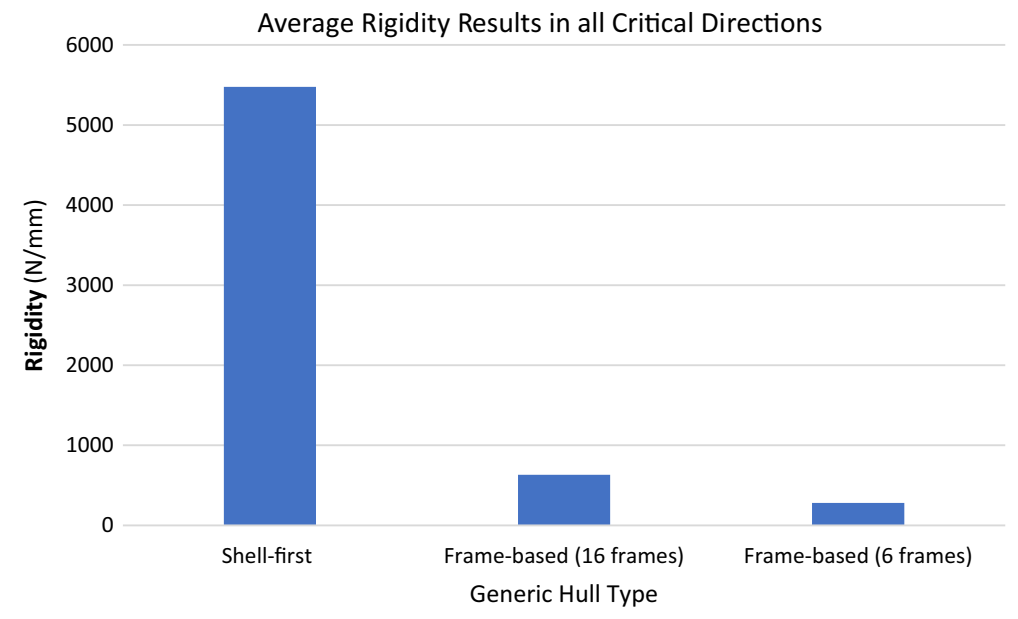

Fig. 7 Average rigidity results in all critical directions

for an 'idealized' experimental environment rather than random inconsistency, schemes were adopted which employed an 'idealized' generic hull containing idealized and generic components. This methodolgy of idealizing, simplifying and neglecting the irrelevant, is a common engineering practice when analyzing systems as complex as an ancient ship. Relevancy is not a quantifiable entity, and its evaluation is left to the designer of an experiment who must judiciously select or reject applicable variables. What is relevant in one design may be irrelevant in another.

Thus, the Dor 2001/1, as an archetypical model (Reith 2008:46), served as the basis of the symplified hull from which the authors sought to extrapolate generalities regarding frame-based constructon. The abundance of representative frame-based variations will provide the basis for future archaeological-engineering research. The hull planking was kept at a constant thickness of $25 \mathrm{~mm}$, roughly corresponding to the average plank thicknesses of the Dor 2001/1 (Kahanov and Mor 2014:51). In order to simulate the edge-to-edge relationship between the frame-based planks, the FEA concept of 'no-penetration contact' was employed, enabling friction surfaces between the hull planks. This type of contact configuration between strakes and frames served to simulate fixed nailed joints, while allowing relative motion between the strake edges. Similarly to the preceding analysis, a onequarter symmetrical hull slice, $5 \mathrm{~m}$ in length, composed of 11 strakes joined to the hull was utilized with 'bonded-contact', another FEA tool which simulates the elimination of relative motion. The $5 \mathrm{~m}$-long symmetrical model represented a $10 \mathrm{~m}$-long ship, being about 30\% less than the length of the Dor 2001/1. Frame cross-section dimensions were $62 \mathrm{~mm}$ molded and $70 \mathrm{~mm}$ sided. The frames were joined to the keel using bonded-contact between the keel and frames.

The experiment was devised to examine the effect of manipulating and re-configuring 'generic stringers' joined to the hull frames, while varying the number of frames. Structural integrity - rigidities and von Mises stresses — was then assesed. Due to the wide range of cross-sectional ceiling plank dimensions of the Dor 2001/1, the six generic stringers were averaged to $49 \mathrm{~mm}$ thick, $267 \mathrm{~mm}$ wide and $4.8 \mathrm{~m}$ in length; they were contact-bonded to the transverse frames with FEA 'no-penetration contact' at their edges. Each generic 
Fig. 8 Basic generic hull model (6 frames, 6 generic stringers)

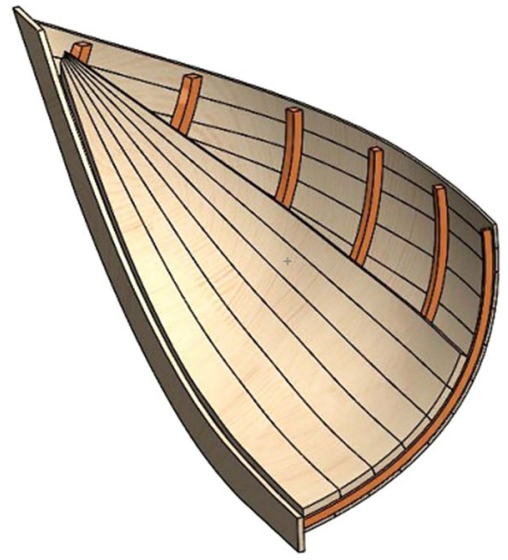

stringer was tapered to a point towards the bow. Frame cross-sections were scaled down, affording the rigidity and strength of frames similar to the Dor 2001/1 (Fig. 8).

Moisture content is a significant factor in measuring the behavior of wood under loaded conditions. Below fiber saturation point, mechanical properties vary inversely with the moisture content (Gutekin and Aydin 2013:878-883). The value of 25\% moisture content, assumed for the purpose of analysing the comparison of structures, was based on measurements made on the planking used for the Ma'agan Mikhael II replica ship. (Tresman, personal communication, 2016). The reported value of $25 \%$ moisture content extended beyond published data (Table 1), hence, all the FEA mechanical property tables relating to strength of materials were extrapolated from the table and then calibrated in the software. Prolonged immersion of the ship's timbers in sea water would result in the wood reaching saturation point $(\sim 30 \%)$, which would significantly affect its mechanical properties.

The building blocks of FEA are discreticized elemental structures assembled into an assembly of elements. This is a process of subdividing systems into their individual elements, whose composite behavior becomes readily understood (Zienkiewicz et al. 2013:1). This assembly, otherwise known as 'a mesh', requires an optimization process termed 'convergence'. This optimization is intended to achieve the most accurate simulation with the appropriate number of elements, element type, and dimensions. The generic models for this study were optimized to contain about 40,000 elements of high quality tetrahedral mesh with an average individual size of $10 \mathrm{~cm}$ (Fig. 9).

In these generic simulations there was no attempt to simulate sea or hydrostatic conditions, as were performed on the global analyses. The loading regime and methodology were 'linear-static', that is, all forces are balanced and there is no motion. This approach was intended to apply a set of loads on the construction which were both concentrated

Table 1 Effects of moisture content on mechanical properties of clear wood at $20^{\circ} \mathrm{C}$ (Gerhards, 1982)

Mechanical property
Relative change in property from 20 to $25 \%$ moisture content
Modulus of elasticity parallel-to-the-grain

Tensile strength parallel-to-the-grain

Compressive strength parallel-to-the-grain

$$
\begin{aligned}
& -13 \% \\
& -15 \% \\
& -35 \%
\end{aligned}
$$




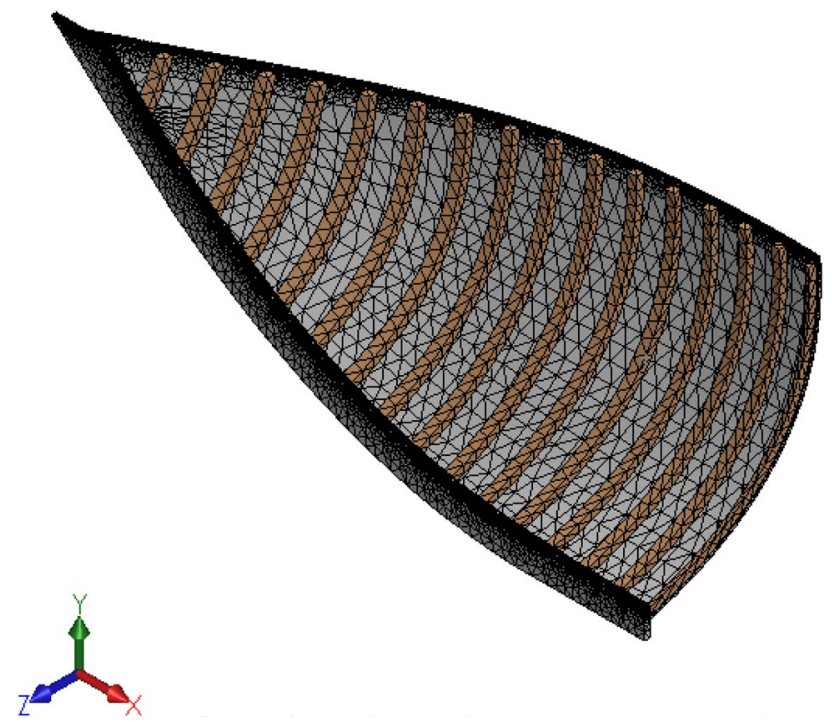

Fig. 9 Meshing strategy of archetypal simulations (16 frames)

and distributed in the spatial directions $+\mathrm{X},-\mathrm{Y},+\mathrm{Y}$ and $+\mathrm{Z}$ (Figs. 3, 5). The sampling method was based on a standard FEA method recommended by the American Bureau of Shipping (American Bureau of Shipping [ABS] 2014:29). At locations of maximum von Mises stresses and displacements, 10 random samples within a $20 \mathrm{~cm}$ radius were averaged. Stiffness/rigidity values were sampled in the same manner, and calculated based on Eq. 1, i.e., maximum load applied, divided by the resulting maximum displacement. Intuitively, the lower the displacement, the higher would be the stiffness/rigidity.

Given this initial experimental load regime (Scheme 1), generic stringers were progressively added to the hull for $0,1,3$, and 6 stringers for both the six-framed and 16-framed generic hulls (Fig. 10). The base line rigidity and von Mises yield values were derived from a previous experiment which had no generic stringers (Helfman et al. 2018:91).

The nature of experimentation must take into account unexpected results in its execution, necessitating adjustments to methodology. All FEA runs yielded generally linear progressions: as frames and stringers are added, von Mises decreased while rigidity increased. However, during the 16 frame rigidity runs, there appeared a rapid order of

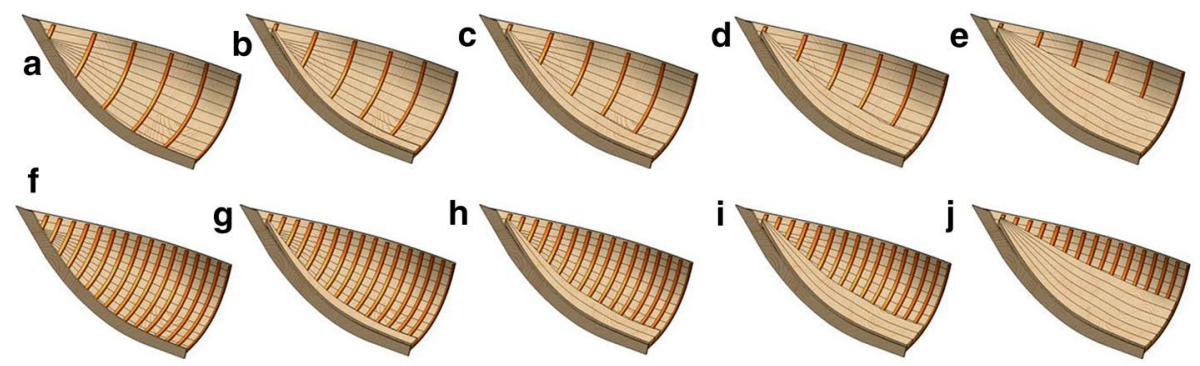

Fig. 10 Scheme $1-+\mathrm{X},-\mathrm{Y},+\mathrm{Y},+\mathrm{Z}$ loads; a-e 6 frames, $0-6$ GSs; f-j 16 frames, $0-6$ generic stringers 

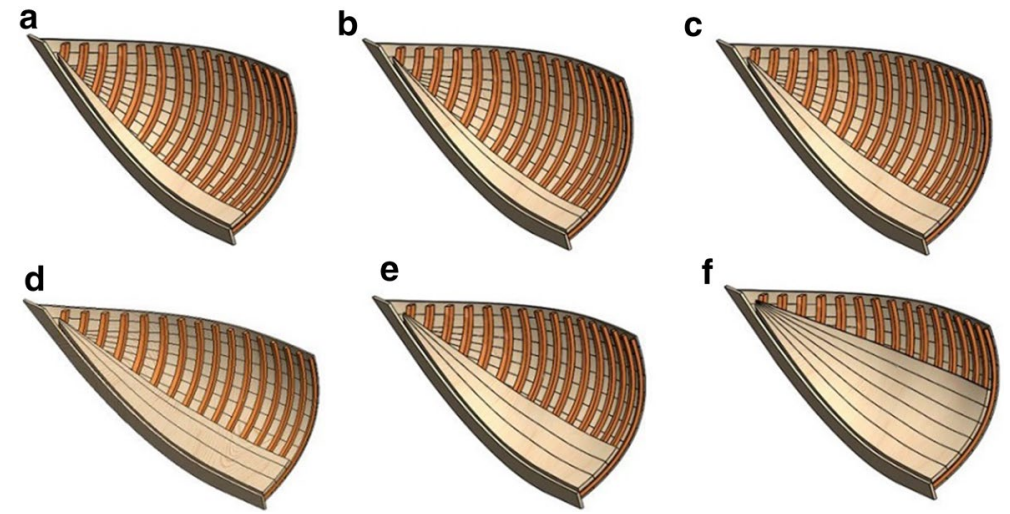

Fig. 11 Scheme 2-evaluating rate of change spike, $+\mathrm{Z}$ load (16 frames); a GS1; b GS1+GS1.5; c GS1 + GS2; d GS1 + GS2 + GS2.5; e GS1 + GS2 + GS3; f GS1-GS6

Fig. 12 Scheme $3-+\mathrm{Z}$ load (16 frames): a GS0; b GS1; c GS3; d GS6
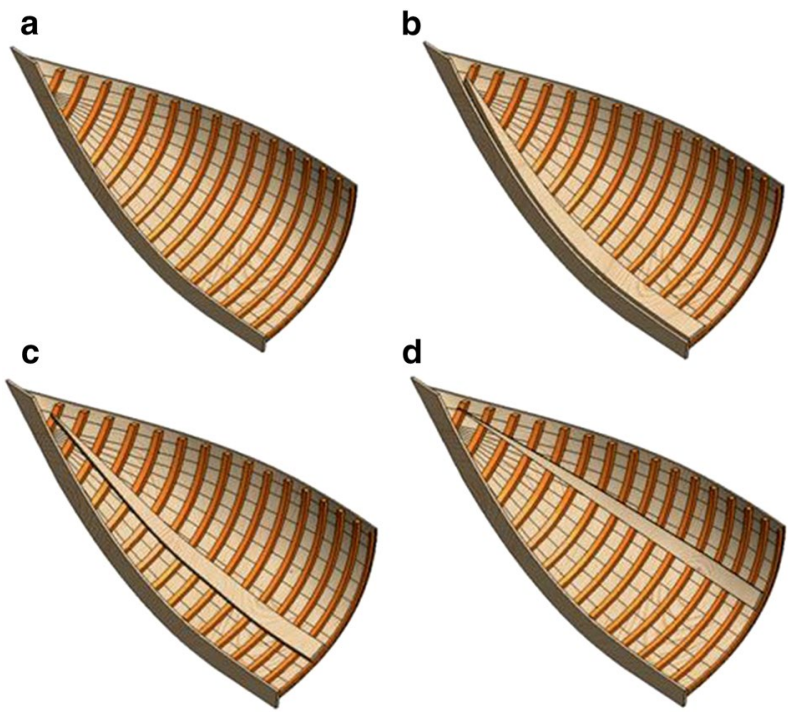

magnitude change in rigidity in the 1-3 generic stringer interval in the $+\mathrm{Z},+\mathrm{Y}$ and - Y loads (Fig. 14). With the objective of resolving this non-linear anomaly, a secondary experimental scheme of higher resolution was devised (Scheme 2) by adding generic stringers with relative incremental width increases of $50 \%$. Hence, the secondary scheme contained the progressive addition of stringers $0,1,1.5,2,2.5,3$ (Fig. 11).

To further explore the phenomenon, Scheme 3 was developed which addressed the question of whether generic stringer location was a variable influencing rigidity and von Mises stress. This third program, also consisting of 16 frames, loaded in the $+\mathrm{Z}$ direction, began at the baseline of stringer 0 (GS0), and progressed with single stringers located at positions GS1, GS3, and GS6 (Fig. 12). 


\section{Results}

\section{Scheme 1}

\section{Von Mises Stress Levels}

Scheme 1 (Fig. 10), for both the 6-frame and 16-frame generic hulls, involved the vertical addition of generic stringers (GS). Based on the load regime of $+\mathrm{X},-\mathrm{Y},+\mathrm{Y}$, and $+\mathrm{Z}$ (Fig. 5), with the increase in the number of stringers and frames, there was a generally linear decrease in von Mises stress levels. In comparing the extreme end sample results, i.e., zero generic stringers with 6 frames to 6 generic stringers with 16 frame configurations, a 13.5-fold decrease in von Mises stress was recorded (43.1 MPa to $3.2 \mathrm{MPa}$ ). The yield level of Pinus brutia (the generic stringer material) is $41.5 \mathrm{MPa}$, while that of Quercus petraea is $74.7 \mathrm{MPa}$ (the frame material). Twenty data sample measurements were extracted from each construction type and averaged (Figs. 13, 14).

\section{Rigidity}

Under the $+\mathrm{X},-\mathrm{Y},+\mathrm{Y}$, and $+\mathrm{Z}$ load regime, rigidity results for the 6-frame model were generally linear, i.e., with the increase in number of frames, there was a consistent increase in rigidity (Fig. 15). However, although the $+\mathrm{X},-\mathrm{Y},+\mathrm{Y}$ results were linearily consistent, under the $+\mathrm{Z}$ load, 16-frame distributed load on the external hull, a significant rate of change in rigidity was revealed in the transition from GS1 to GS3 (Fig. 16). This seemingly anomalous non-linear behavior of an order of magnitude spike was treated in Scheme 2 by adding half-width stingers between these two generic stringers (Fig. 11). The objective of the experiment was to smooth the curve and thereby isolate the points of incremental change (Table 2).

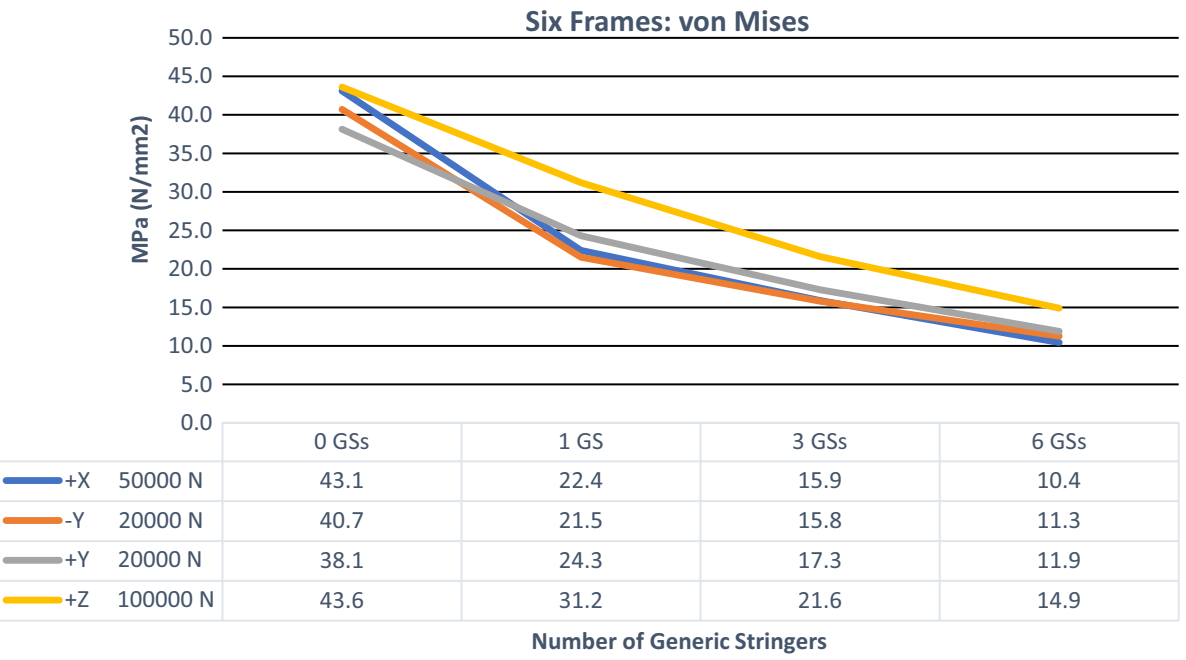

Fig. 13 Scheme 1-von Mises stress results from 0-6 generic stringers by 6 frames 


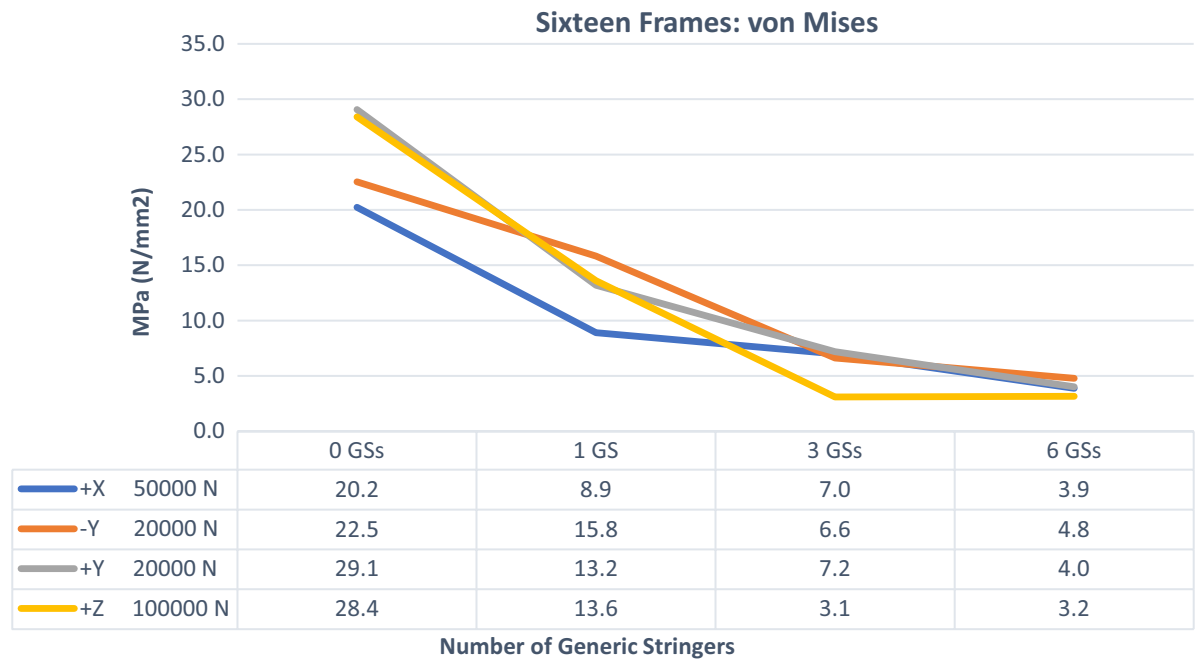

Fig. 14 Scheme 1-von Mises stress results for 0-6 generic stringers by 16 frames

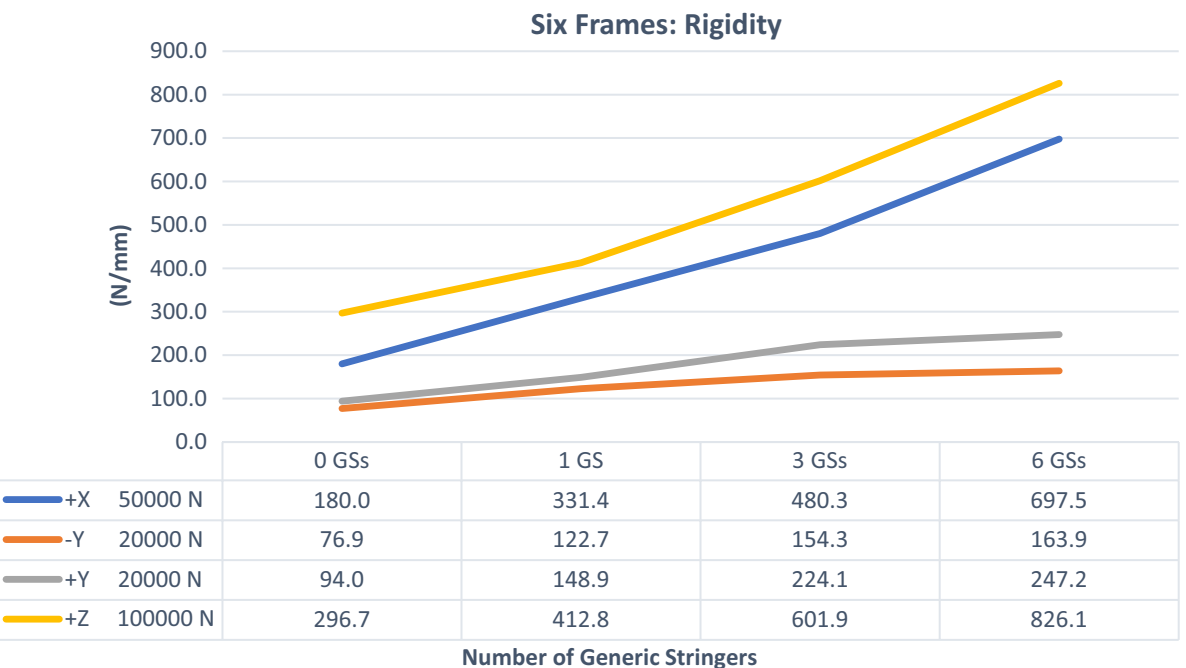

Fig. 15 Scheme 1-Rigidity results for 0-6 generic stringers by 6 frames

\section{Scheme 2 (16 Frames Incremental Generic Stringers Addition: +Z)}

\section{Von Mises Stress Levels}

In Scheme 2 (+ Z load, 16 frames), at the interval between GS1 and GS3, wherein halfwidth stingers were incrementally added, the von Mises stress results paralleled and overlapped the results exhibited by the original Scheme 1. By GS2, stress levels flattened out and remained constant until GS6 (Fig. 17). 


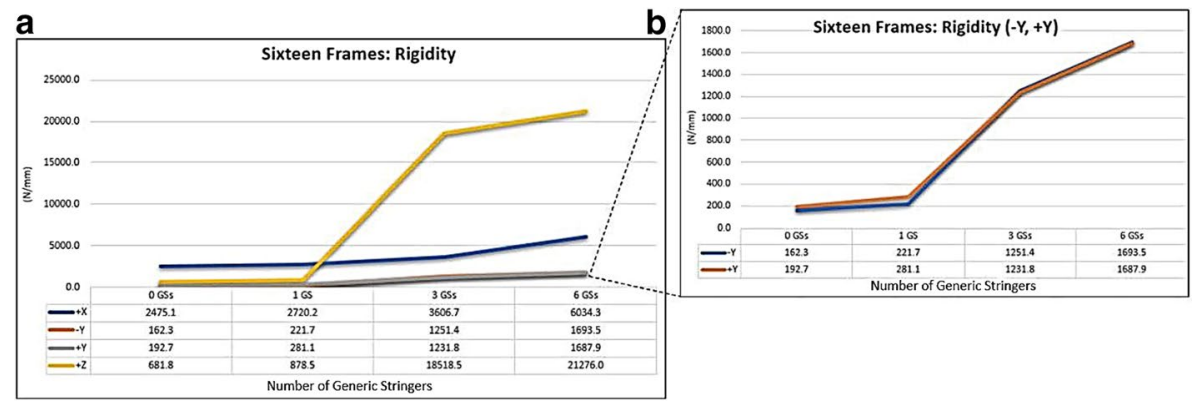

Fig. 16 Scheme $1-\mathbf{a}$ 16-frame rigidity result with significant spike for $+Z$ loads; $\mathbf{b}$ re-scaled detail of $-\mathrm{Y}$ and + Y loads

Table 2 Experimental scheme descriptions

\begin{tabular}{llll}
\hline Scheme & Description & No. of frames & Figure no. \\
\hline 1 & Vertical incremental addition of generic stringers & 6,16 & 10 \\
2 & $\begin{array}{l}\text { Testing rapid spike in rigidity; vertical incremental } \\
\text { addition of half-width generic stringers }\end{array}$ & 16 & 11 \\
3 & $\begin{array}{l}\text { Addressing influence of generic stringer placement } \\
\text { on rigidity; vertical incremental addition of single } \\
\end{array}$ & 16 & 12 \\
& generic stringers & & \\
\hline
\end{tabular}

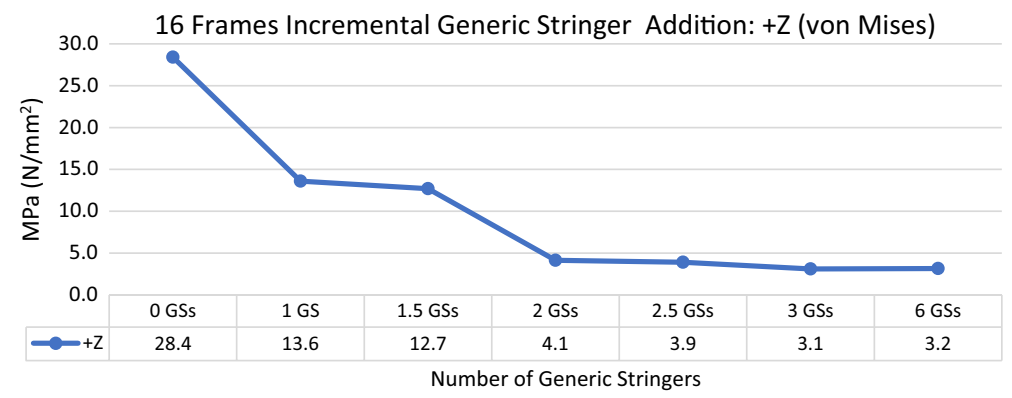

Fig. 17 Scheme 2-testing $+Z$ loads for von Mises stresses on incremental half-step

\section{Rigidity}

The rigidity testing in Scheme 2 ( $\mathrm{Z}$ load, 16 frames), although at a higher resolution, overlapped the results from Scheme 1 (Fig. 16a): the structural rigidity gradient reached its peak with the addition of GS2, and at that point leveled off and remained nearly constant through GS6 (Fig. 18). 


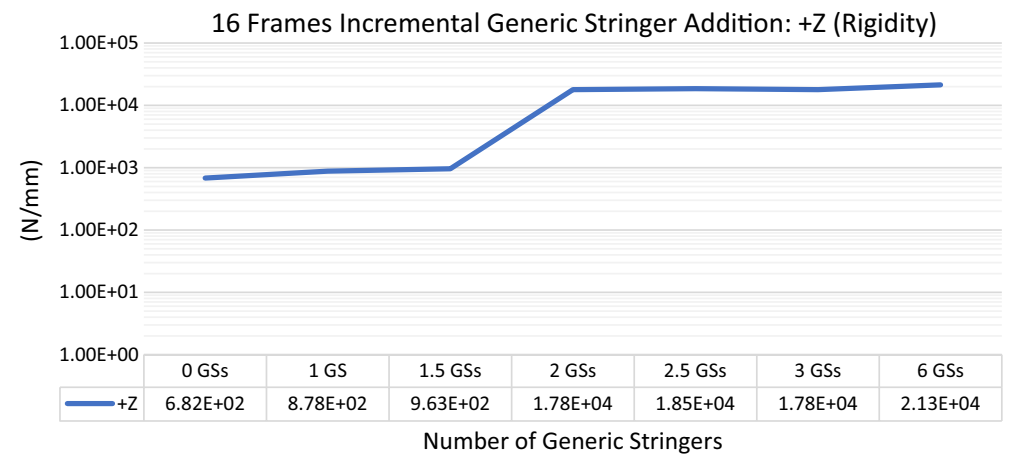

Fig. 18 Scheme 2 -testing $+Z$ loads for rigidity on incremental half-step increases of generic stringers (vertical logarithmic scale)

\section{Scheme 3 (16 Frames Single Generic Stringer Location: +Z)}

\section{Von Mises Stress Levels}

Scheme 3, consisting of 16 frames applied in the $+\mathrm{Z}$ direction, addressed the question of whether single generic stringer location was a variable influencing von Mises stresses. The analyses were conducted on isolated generic stringers GS1, GS3, and GS6 (Fig. 10). Although, as expected, the GS0 and GS1 positions were identical to the Scheme 1 results, a 50\% stress reduction was achieved when locating a single generic stringer at GS3. This reduction trend was likewise maintained (43\% stress reduction) by locating a single generic stringer at GS6. Although, by comparison, the singular generic stringer von Mises stress reductions (Scheme 3) were less than both the Scheme 1 and the Scheme 2 paradigms ( 89\%), the results were noteworthy (Fig. 19).

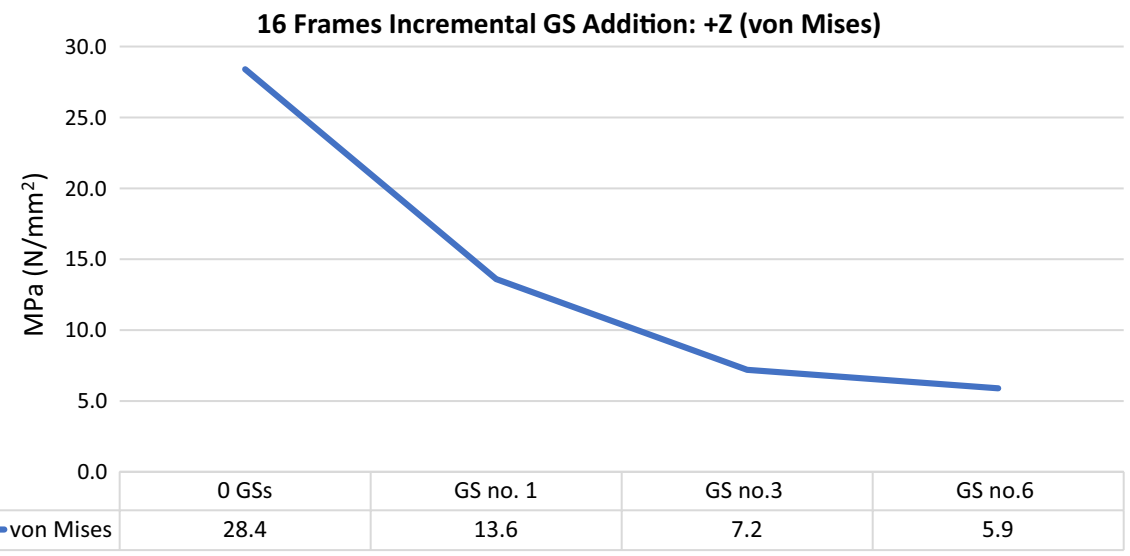

GS Location

Fig. 19 Scheme 3-testing $+Z$ loads for von Mises stresses, single location generic stringer reinforcement 


\section{Rigidity}

The results for the rigidity testing in Scheme 3, also as expected, remained identical to the Scheme 1 results for locations GS0 and GS1. Again, the same rigidity gradient spike was revealed with the placement of GS3, leveling off at a higher level of structural rigidity on GS6. Rigidity at the locations GS3 and GS6 increased at an average of $220 \%$ as compared to $320 \%$ in the Scheme 1 (Fig. 20).

\section{Discussion}

The departure point of the current study was the end point of a previous comparative study (Helfman et al. 2018:102), which demonstrated that in its basic structural configuration, the shell-first hull construction method possessed mechanical and engineering advantages over the frame-based method. From the intuitive notion that longitudinal reinforcements may increase structural integrity in the frame-based ship (Pomey et al. 2012:236), by applying structural engineering principles and employing finite element analysis, it was demonstrated that the insertion of longitudinal reinforcements in the form of generic stringers was required to bring about structural equivalence between the two methods. The locations of key stringers in real-world examples coordinates well with their analyses.

The generic nature of the experimental methodology required ignoring specific types of longitudinal reinforcement such as keelsons, sister-keelsons and wales, which also provide longitudinal strengthening. In pursuit of comprehending wooden hull structural integrity, it is apparent however, that the significant contribution of these components requires further and extensive research beyond the scope of the current study.

To achieve parity with the shell-first structure, the addition of reinforcements to the frame-based structure had to meet two criteria: equal levels of rigidity and stress. Comparing the optimal values of the von Mises stress of a distributed load of 100,000 MPa on the external side of the hull ( $\mathrm{Z}$ direction) for the two archetypical vessels, the shellfirst achieved 3.4 MPa, while the frame-based achieved 3.2 MPa. Rigidity results also

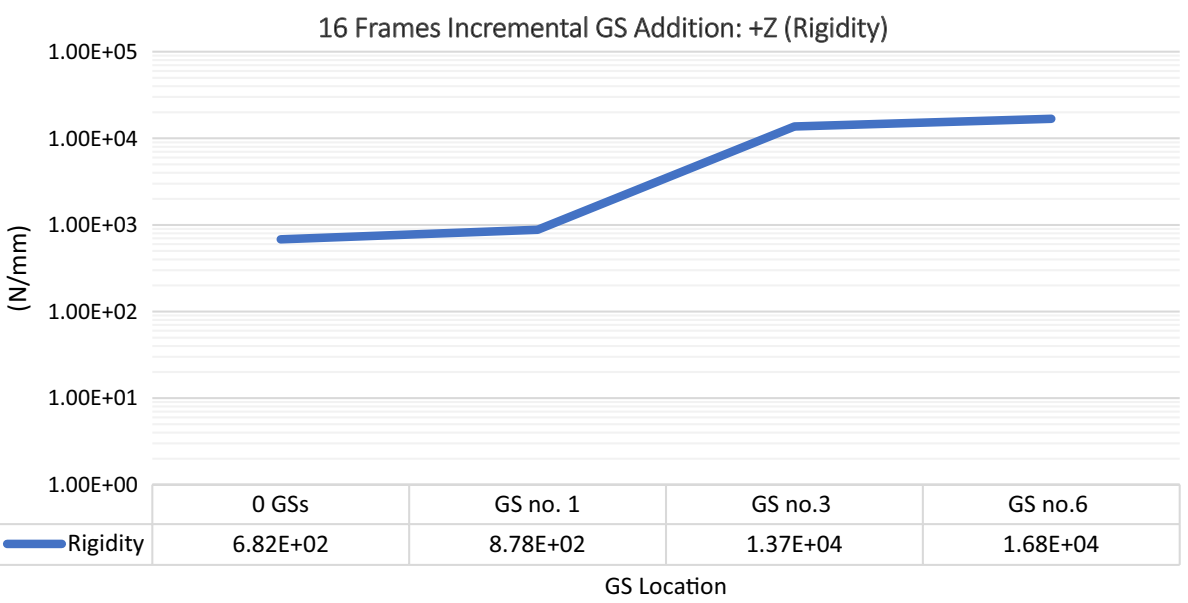

Fig. 20 Scheme 3 -testing $+Z$ loads for rigidity, single location generic stringer reinforcement 
demonstrated equivalence, with the shell-first at 19,739,000 N/mm and the frame-based at $21,276,000 \mathrm{~N} / \mathrm{mm}$ (Fig. 13). Hence, the hypothesis 'increasing the number of hull frames and longitudinal reinforcements sufficed to establish mechanical-structural equivalence between shell-first and frame-based ship hulls' can be clearly affirmed.

In all the rigidity test runs performed in the current study, the significant gradient spikes registered between GS1 and GS3 must be addressed. This was made salient particularly in the runs analyzing hull rigidity against specific stringer locations (Scheme 3 ). This placement and dimensioning of stringers can also be seen in the construction of the earliest known fully frame-based shipwreck, the Dor 2001/1. As shown in Fig. 21, clamp C11 is the largest of the ceiling strakes and is located higher than the turn of the bilge. It was joined by iron nails to the framing timbers, and was parallel to the first wale (Kahanov and Mor 2014:54). The calculated moments of inertia ( $\left.\mathrm{I}_{\mathrm{xx}}\right)$ of $\mathrm{C} 11$ is $6.10 \mathrm{E}+07 \mathrm{~mm}^{4}$, while its adjacent plank- $\mathrm{C} 10$, is $1.64 \mathrm{E}+07 \mathrm{~mm}^{4}\left(\mathrm{I}_{\mathrm{xx}}\right)$, thus illustrating their comparitive mechanical and structural differences. One could surmize that by merely increasing the moment of inertia of GS3 or GS6, both rigidity and stress levels would be significantly affected. An initial speculative insight would suggest that the number of generic stringers, their relative location, combined with the number of transverse frames, significantly contributed to the structural integrity and ultimate adoption of frame-based hulls. Further, this demonstrates that the ideal location for longitudinal timbers to strengthen a hull's structural integrity is just above the bilge, and this location coordinates well with many real-world examples of stringers and clamps in that location. This most likely indicates that shipwrights of the past had come to the same conclusion. This observation has both archaeological and structuralengineering significance worthy of further exploration.

Frame-based ships like the Dor 2001/1, Tantura A and later ships, such as the Serçe Limanı, evolved and adopted a highly systematic construction technique determined by mathematical formulae. Ships were no longer 'shaped by eye' hulls, but rather formed by highly delineated

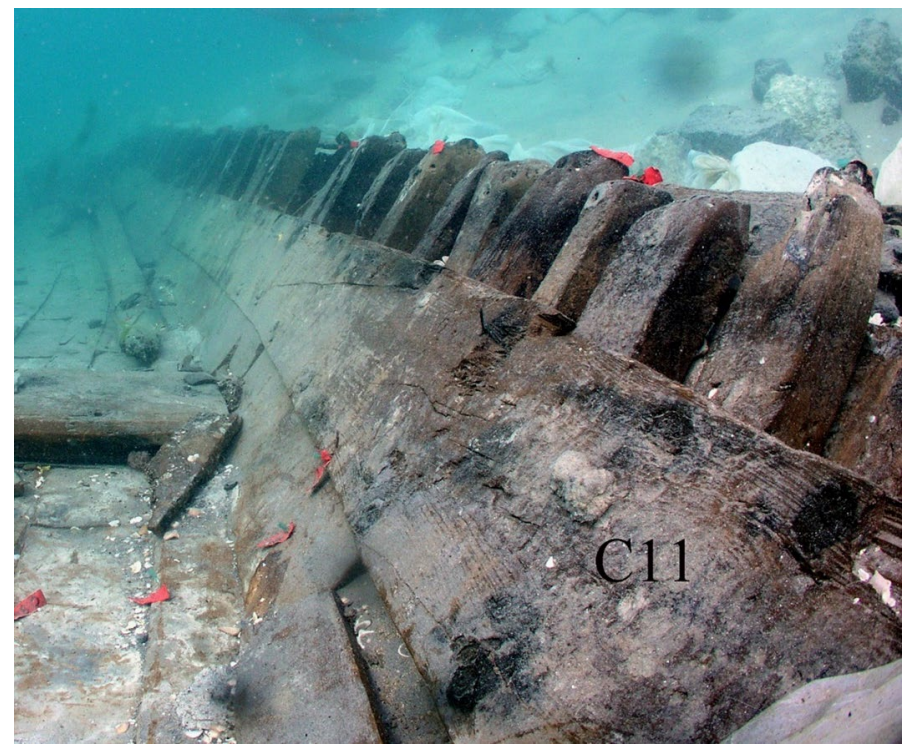

Fig. 21 Ceiling plank C11 of the Dor 2001/1 shipwreck, showing its placement above the turn of the bilge. The view is to the north-west of the north-eastern side (Photo: S. Breitstein) 
sets of mathematical rules - the partisoni-a method whose rudiments can be traced back to the Bozburun shipwreck (874 AD) (Hocker and McMannon 2006:3; Harpster 2010:53). By the 3rd and 4th Crusades, Genoa and Venice had become industrial centers producing vessels at a rate of hundreds of frame-based ships per year (Lane, 2010). As the Renaissance unfolded, the extended scale of mass production of frame-based ships resulted in a shift from independent business to a large-scale industry, employing division of labor. Social stratification ensued, distinguishing between the manual laborer and the entrepreneur. This 'economics of scale', based on frame-based construction, robbed the craftsman of his individual self-reliance, shifting the economy to a communal organization (Lane 2010:101).

There is an ecological liaison between forestry and economic history, as witnessed by the Venetian Arsenal's insatiable consumption of timber. There existed pressures of de-forestation, and the management of tree species, while price fluctuations were dependent on raw materials, either imported or shipped (Lane 2010:223). As the frame-based technology developed, its impact could have hardly been appreciated, evolving to be ideally suited to mass-production. One could speculate that manufacturing did not beget the frame-based technology, but rather, the frame-base's systematic essence was the primordial mother of modern manufacturing.

\section{Conclusions}

Through a simulated FEA set of studies, it has been shown that the insertion of longitudinal wooden reinforcements connected to the frames contributes to the mechanical-structural integrity of a frame-based hull. The analyses demonstrate that the ideal location was just above the bilge, a location that coordinates well with many real-world examples of stringers and clamps. The improved structural integrity was manifested in increased rigidity and reduced von Mises stresses in all the experimental load regimes. Hence, there are three mutually interdependent variables determining these structural properties: the number of generic stringers, their location, and the number of transverse frames. It should also be noted that although the technological solultions presented here are centered about the Eastern Mediterranean, ship construction revealed from extant shipwrecks elsewhere indicate similar solutions throughout the Mediterranean.

Acknowledgements This study was supported by a Sir Maurice Hatter Fellowship. The authors are grateful to J. B. Tresman for the English editing, and to the anonymous reviewers for their valuable comments and suggestions.

Open Access This article is distributed under the terms of the Creative Commons Attribution 4.0 International License (http://creativecommons.org/licenses/by/4.0/), which permits use, duplication, adaptation, distribution and reproduction in any medium or format, as long as you give appropriate credit to the original author(s) and the source, provide a link to the Creative Commons license, and indicate if changes were made.

\section{Appendix: Glossary}

The terms defined below are derived from various mechanical engineering texts that deal primarily in structural engineering and finite element analysis (Shigley et al. 2004; Ross et al. 2016; Rigo and Rizzutto 2003): 


\section{Contact Sets}

Contact sets define the method by which assembly components are connected to each other. Examples are:

- Bonded contact: two parts behave as if they are welded together, eliminating any relative motion between them.

- No penetration: a contact set which prevents interference between parts but allows gaps to form. A factor of friction can be added between them.

\section{Deflection}

Deflection is the degree to which a structural element is displaced under a load.

\section{Finite Element Analysis (FEA)}

Finite Element Analysis (FEA) is a method by which a large engineering problem is divided into smaller simpler parts called finite elements. The simple equations that model these finite elements are then assembled into a larger system of equations that models the entire problem.

\section{Load}

Structural loads are forces exerted on a body or surface.

\section{Megapascal}

A pascal is the unit of pressure used to quantify pressure, internal stress, and ultimate tensile strength. It is defined as $1 \mathrm{~N}$ per 1 square meter.

1 Megapascal $(\mathrm{MPa})=10^{6}$ pascals.

\section{Moment of Inertia}

An indication of resistance to bending measured as the cross-sectional moment of area. Moment of inertia is measured in $\mathrm{N} / \mathrm{mm}^{4}$.

\section{Newton Force}

One newton of force $(\mathrm{N})$ is the force required to accelerate an object with a mass of $1 \mathrm{~kg}$ at a rate of $1 \mathrm{~m}$ per second per second.

\section{Rigidity/Stiffness}

A structure or mechanical element is said to possess rigidity/stiffness when it does not bend or deflect. Rigidity/stiffness is measured in N/mm. Loads in stillwater include external hydrostatic pressure while considering waves. 


\section{Stress}

Stress is the force (strength or energy) exerted on an object, divided by its cross-sectional area. It is a physical quantity that expresses the internal forces that neighboring particles of a continuous material exert on each other. Stress is measured in newtons per square millimeter.

\section{von Mises-Hencky Theory}

Von Mises stress is a value used to determine if a given material will yield or fracture.

Yield strength or yield stress is the material property defined as the stress at which a material begins to deform plastically.

\section{References}

Adams J (2003) Ships, innovation and social change: aspects of carvel shipbuilding in Northern Europe 1450 - 1850. University of Stockholm, Stockholm

American Bureau of Shipping [ABS] (2014) Safehull finite element analysis of hull structures, Latest edn. American Bureau of Shipping, Houston

DNV GL (2015) Yachts, part 3 hull, hull designs. In: Rules for classification. Oslo: DNV GL standards publication, pp 3-35

Gerhards CC (1982) Effect of moisture content and temperature on the mechanical properties of wood: an analysis of immediate effects. Wood Fiber Sci 14(1):4-36

Gutekin E, Aydin TY (2013) Effects of moisture content on some mechanical properties of Turkish red pine (Pinus brutia). Artvin Çoruh University, Artvin

Helfman N, Nishri B, Cvikel D (2018) A comparative structural analysis of shell-first and frame-based ship hulls of the 1st millennium AD. Naval Eng J 130:91-103

Hocker FM, McMannon JM (2006) Mediaeval shipbuilding in the mediterranean and written culture at Venice. Mediterr Hist Rev 21(1):1-37

Hockmann O (1993) Late Roman Rhine vessels from Mainz, Germany. Int J Naut Archaeol 22(2):125-135

Kahanov Y, Mor H (2014) The Dor 2001/1 Byzantine shipwreck, Israel; final report. Int J Naut Archaeol 43(1):41-65

Lane FC (2010) Venetian ships and shipbuilders of the renaissance. John Hopkins University Press, Baltimore

Linder E, Kahanov Y, Black E (2003) The hull. In: The Ma'agan Mikhael Ship, the recovery of a 2400-year-old merchantman: final report, vol 1. Israel Exploration Society and University of Haifa, Jerusalem, pp 51-147

Linder E, Kahanov Y, Black E (2004) Conclusions. In: The Ma'agan Mikhael Ship, the recovery of a 2400-year-old merchantman: final report, vol 2. Israel Exploration Society and University of Haifa, Jerusalem, pp 243-245

Pomey P, Kahanov Y, Reith E (2012) Transition from shell to skeleton in ancient mediterranean ship-construction: analysis, problems, and future research. Int J Nautical Archaeol 41(2):235-314

Reith E (2008) Géométrie des formes de carène et construction "sur membrure première"(Ve-XIIe siècle): une autre approche de l'histoire de l'architecture navale méditerranéenne au Moyen age? Archaeol Marit Mediterr 5:45-68

Rigo P, Rizzutto E (2003) Analysis and Design of Ship Structure. In: Lamb T (ed) Ship design and construction, vol 1. Attica, SNAME, pp 18-76

Ross C, Bird J, Little A (2016) Mechanics of solids. Routledge, London

Shigley J, Mischke CR, Budynas RG (2004) Mechanical engineering design. First metric, Edition edn. McGraw-Hill, New York

van Doorninck FH Jr (1976) The 4th century wreck at Yassi Ada An interim report on the hull. Int J Naut Archaeol 5(2):115-131

Zienkiewicz OC, Taylor RL, Zhu JZ (2013) Finite element method: its basis and fundamentals: its basis and fundamentals, 6 th edn. Elsevier, Swansea

Publisher's Note Springer Nature remains neutral with regard to jurisdictional claims in published maps and institutional affiliations. 